\title{
CRÓNICA DE LA ELECCIÓN PRESIDENCIAL EN CHILE (DICIEMBRE-1999 Y ENERO-2000)
}

\author{
FRANCISCO ZÚÑIGA URBINA \\ Profesor de Derecho Constitucional y Político \\ Universidad Central de Chile
}

CARLOS GUTIÉRREZ MOYA

Profesor Ayudante

Universidad Central de Chile y Universidad La República de Chile 


\section{SUMARIO}

1. El sistema electoral Chileno. 2. Las candidaturas presidenciales. 2.1. Fuerzas políticas. 2.2. Programas de gobierno. 2.3. Campañas presidenciales. 2.3.1. Propagandas electorales. 2.3.2. Encuestas. 3. LOS RESULTADOS electorales en la PRIMERA vUelta. 3.1. Cuadros estadísticos de los resultados. 3.1.1. Cuadro por regiones. 3.1.2. Cuadro de varones y mujeres. 3.2. Análisis de los resultados. 4. LAS REACCIONES Y ESTRATEGIAS DE LAS DOS CANDIDATURAS QUE OBTUVIERON LAS MÁS altaS MaYoRIAS RELATIVAS. 5. ResULTADOS ELECTORALES EN LA SEgUNDA VUELTA. 5.1. Cuadros estadísticos de los resultados. 5.1.1. Cuadro por regiones. 5.1.2. Cuadro de varones y mujeres. 5.1.3. Cuadro de la votación de varones y mujeres en las elecciones de diciembre-1999/enero-2000 en relación con la de 1993. 5.1.4. Cuadro de las elecciones de diciembre-1999/enero-2000 en relación con las de 1989 y 1993. 6. LAS REPERCUSIONES POLITICAS. 


\section{CRÓNICA DE LA ELECCIÓN PRESIDENCIAL EN CHILE (DICIEMBRE-1999 Y ENERO-2000)}

POR

FRANCISCO ZÚÑIGA URBINA Y CARLOS GUTIÉRREZ MOYA

Profesor de Derecho Constitucional y Político

Universidad Central de Chile

Profesor ayudante

Universidad Central de Chile y

Universidad La República de Chile

\section{EL SISTEMA ELECTORAL CHILENO}

Los días 12 de diciembre de $1999^{1}$ y 16 de enero del año $2000^{2}$, se celebró en Chile la elección presidencial de acuerdo con lo previsto en el art. 26.1 de la Constitución Política de la República, que prescribe «EI Presidente de la República será elegido en votación directa y por mayoría absoluta de los sufragios válidamente emitidos. La elección se realizará en la forma que determine la ley, noventa días antes de aquel en que deba cesar en el cargo el que esté en funciones». Cabe además tener presente que el inciso segundo de este precepto constitucional ordena que "Si a la elección de Presidente de la República se presentaren más de dos candidatos y ninguno de ellos obtuviere más de la mitad de los sufragios válidamente emitidos, se procederá a una segunda votación que se circunscribirá a los candidatos que hayan obte-

1 Primera vuelta.

2 Segunda vueita. 
nido las dos más altas mayorías relativas $y$ en ella resultará electo aquel de los candidatos que obtenga el mayor número de sufragios. Esta nueva votación se verificará, en la forma que determine la ley, el trigésimo día después de efectuada la primera, si ese día correspondiere a un domingo. Si así no fuere, ella se realizará el domingo inmediatamente siguiente al referido trigésimo día".

La norma jurídica aludida por la Carta Fundamental es la Ley N. ${ }^{\circ}$ $18.700^{3}$, ley orgánica constitucional ${ }^{4}$ sobre Votaciones Populares y Escrutinios, que regula los procedimientos para la preparación, realización, escrutinio y calificación de los plebiscitos y de las elecciones de Presidente de la República y Parlamentarios (art. $1 .^{\circ}$ ). En el sistema electoral chileno, las candidaturas a Presidente de la República deben cumplir con los trámites formales de declaración e inscripción. La declaración de cada candidatura a Presidente de la República debe efectuarse por escrito (art. $3 .^{\circ}$ ), y el patrocinio de las candidaturas independientes debe suscribirse ante notario por un número de ciudadanos, inscritos en cualquier parte del territorio nacional, no inferior al 0,5 por ciento de los que hubieren sufragado en la anterior elección periódica de Diputados 5 (art. 13). Las declaraciones de candidaturas de partidos políticos deben ser suscritas por el Presidente y el Secretario de la Directiva Central de cada partido político, y además, debe cumplir los requisitos especiales de que sólo pueden ser declarados por los partidos políticos constituidos en todas las regiones del pais, o en su defecto, que acrediten una cantidad total de afiliados en las regiones en que se encuentran legalmente constituidos no inferior al 0,5 por ciento ${ }^{6}$ (art. 14). Las declaraciones deben ser presentadas ante el Director del Servicio Electoral o el respectivo Director Regional del Servicio Electoral (art. 3. .1). Las declaraciones de candidaturas a Presidente de la República deberán ser aceptadas o rechazadas por el Director del Servicio Electoral, dentro del plazo de diez días siguientes a aquél en que venza el plazo para la declaración de las candidaturas, mediante resoluciones administrativas que se publicarán dentro de tercero día en el Diario Ofi-

$3 \quad$ Publicada en el Diario Oficial de 6 de mayo de 1988.

4 El art. 63.2 de la Carta Fundamental señala que las normas legales a las cuales la Constitución confiere el carácter de ley orgánica constitucional requerirán, para su aprobación, modificación o derogación, de las cuatro séptimas partes de los diputados y senadores en ejercicio.

5 De acuerdo con el escrutinio general practicado por el Tribunal Calificador de Elecciones.

6 Establecido de la misma manera indicada para las candidaturas de independientes a Presidente de la República. 
cial (art. 17). Dentro de los tres días siguientes de vencido el plazo de cinco días ${ }^{7}$ que los agraviados tienen para reclamar en contra de la resolución que rechaza su candidatura, o del fallo del Tribunal Calificador de Elecciones, el Director del Servicio Electoral debe inscribir las candidaturas en un registro especial, y desde ese momento se considera que los candidatos tienen la calidad de tales para todos los efectos legales (art. 19.1). Al tercer día de expirado el plazo para inscribir las candidaturas, el Director del Servicio Electoral determina el orden de precedencia de los candidatos en la respectiva cédula electoral oficial, mediante sorteo en audiencia pública (art. 23).

\section{LAS CANDIDATURAS PRESIDENCIALES}

\subsection{Fuerzas políticas}

La ley $\mathrm{N}^{\circ} 18.700$ permite expresamente a los partidos políticos acordar integrar pactos electorales. La centro-derecha que en la actualidad es oposición al gobierno, está conformada por los partidos políticos Renovación Nacional y Unión Demócrata Independiente, los cuales se unieron para constituir la Alianza por Chile ${ }^{8}$ agrupándose en torno a la figura del popular Joaquín Lavín Infante, sobresaliente alcalde de Las Condes, católico miembro del Opus Dei, ex colaborador del régimen militar, eligiéndolo como su abanderado a través del consenso de los dirigentes de los partidos del pacto. Mientras tanto, la coalición gobernante de centro-izquierda llamada Concertación de Partidos por la Democracia, conformada por los partidos Democracia Cristiana, Liberales, Socialista, Por la democracia,y Radical Social Demócrata decidió dar más participación a las "bases" mediante elecciones primarias que determinaran quién iba a ser su candidato único. Los candidatos a las primarias fueron el socialista Ricardo Lagos Escobar y el demócrata cristiano Andrés Zaldívar ${ }^{9}$, resultando vencedor Lagos por una holgada mayoría con 985.505 votos $(71,34 \%)$ contra 395.821 votos $(28,66 \%)$ obtenidos por Zaldívar ${ }^{10}$, que hizo temer a la Iglesia Católica, Apostólica $\vee$

7 Contado desde la publicación de la resolución que rechaza la declaración de la candidatura.

8 Ex Unión por Chile en 1993.

9 Ambos poseedores de un gran prestigio como tenaces adversarios del régimen autoritario de Augusto Pinochet.

10 El Mercurio, Resultados Primarias Concertación, 31/5/1999, Cuerpo A, pág. 1. 
Romana el advenimiento al gobierno de un líder de pensamiento agnóstico y tolerante ${ }^{11}$. Lagos también fue visto como una amenaza por el empresariado, por el ideario progresista que encarnaba, que aparecía como una remembranza de la traumática experiencia de la Unidad Popular de Salvador Allende cuando llegó al poder a fines de $1970^{12}$. La caída de Zaldivar en las primarias agregó un nuevo ingrediente a la campaña presidencial, pues permitió que la derecha sedujera al electorado católico como garante de sus valores y creencias religiosas. En efecto, el triunfo de Lagos era el pretexto para luchar con más fuerzas contra la coalición de gobierno que ahora aparece liderada por un laico que abiertamente no muestra simpatías por la Iglesia Católica, a diferencia del ex Presidente Patricio Aylwin (1990-1994) y el Presidente en ejercicio Eduardo Frei, ambos católicos y demócrata cristianos. Frente a esta gran desventaja, Lagos dio un golpe de timón acercándose en busca de apoyo a las congregaciones protestantes (evangélicas), que desde siempre han visto con recelo la hegemonía de la Iglesia Católica en Chile, para las cuales Lagos daba mayores garantías de respeto a las libertades de conciencia y culto que el candidato Opus Dei de la centroderecha. Por otra parte, Lavín reaccionó ante la estrategia de Lagos apelando al común denominador de cristianos que compartían los católicos con los fieles protestantes, llamando a la unidad del umundo cristianismo", y en agosto de 1999, la Iglesia Católica interviene a través de Monseñor Jorge Medina, Prefecto de la Curia Vaticana, quien con ocasión de una visita que hizo a Chile manifestó: "los católicos saben por quien pueden votar y por quien no deben votar» ${ }^{13}$. El día 22 de noviembre de 1999, los masones adherentes a la candidatura de Ricardo Lagos realizaron un acto de proclamación en el Salón de Honor del ex Congreso Nacional. Días después la comunidad judía también expresa su preocupación por el repunte en las encuestas del candidato Opus Dei y da muestras claras de preferencia por el candidato agnóstico. Los otros candidatos fueron Arturo Frei Bolívar, un independiente de tendencia política humanista-cristiana que fue expulsado de la Democracia cristiana por haber viajado a Londres a visitar al Senador Pinochet cuando se encontraba detenido, Tomás Hirsch Goldschmidt, por el Partido Humanista; Gladys Marín Millie, por el Partido Comunista del cual es su Secretaria General, y Sara Larraín Ruiz-Tagle, por el Movimiento Ecologista. res católicos.

11 En el sentido negativo, como falto de entereza en la defensa de los valo-

12 Germán Unzúa, Historia Política Electoral de Chile, pág. 157.

13 El Siglo: El Opus Dei tras la estrategia de Joaquín Lavín, pág. 12. 
En la elección presidencial 1999, el orden de los nombres de los seis candidatos inscritos, que resultó del sorteo y que ocuparon en la cédula electoral, fue el siguiente:

\section{LAS CANDIDATURAS PRESIDENCIALES}

Los candidatos presidenciales fueron los siguientes, a saber:

1. Arturo Frei Bolivar;

2. Sara Larraín Ruiz-Tagle;

3. Gladys Marín Millie;

4. Tomás Hirsch Goldschmidt;

5. Ricardo Lagos Escobar;

6. Joaquín Lavín Infante.

\subsection{Programas de gobierno}

La Alianza por Chile elaboró su plan de "60 soluciones del cambio", donde puso énfasis en los problemas socioeconómicos que estaba sufriendo la mayoría de los habitantes del país, poner término a las largas filas que deben soportar los enfermos en los consultorios policlínicos públicos, construir más viviendas, mejorar la educación, aumentar el empleo para disminuir la cesantía, combatir con mano de hierro la delincuencia, las drogas. La centro-derecha responsabilizó al Gobierno por su ineficacia mostrada durante diez años en que prácticamente nada se había hecho, en circunstancias le era posible hacerlo. Por esta razón era necesario "el cambio" de lo que no servía, la Concertación, por lo que funcionaba, la Alianza por Chile.

La Concertación también mencionó los temas anteriormente citados, pero puso más énfasis en la construcción de una visión de Chile con más valores, más justo, con más igualdad y solidaridad, donde la persona valga más por lo que es y no por lo que tiene. Criticó a la centro-derecha por ser insensible y defensora de un modelo económico que explotaba a la gente. Asimismo, se esforzó en destacar la importancia de la consolidación del régimen democráti$\mathrm{co}$, la necesidad de eliminar enclaves autoritarios mediante reformas constitucionales y de que se esclarezcan los hechos y sean castigados quienes hayan cometido violaciones a los derechos humanos. 


\subsection{Campañas presidenciales}

La Alianza por Chile acuñó la simple y efectiva consigna "Viva el cambio' ${ }^{14}$, procurando hacer sentir a los ciudadanos el peso de la frustración por las promesas incumplidas por el gobierno y las necesidades insatisfechas en un año de crisis económica que asoló a todos los sectores de la actividad económica, con inflación, despidos masivos y desempleo muy alto, inseguridad ciudadana respecto a la criminalidad, etc. Joaquín Lavín tomó la iniciativa al comenzar su ucaminata por el cambio" viajó a las ciudades más alejadas de Santiago, y visitó puerta a puerta a los futuros electores, disfrazándose de gente de la zona, de pescador, de araucano, de minero, de huaso, etc. Además, parlamentarios de la oposición de centro-derecha y el mismo Lavín recurrian de manera reiterada a la pregunta retórica que rezaba ¿creen que los mismos que han gobernado durante diez años van a ser capaces de solucionar los problemas reales de la gente?

La Concertación de Partidos por la Democracia, bajo el lema "Crecer con lgualdad" y "Lagos contigo" partió rezagada con relación a la candidatura opositora, debido a la desilusión sufrida por los demócrata-cristianos tras le derrota de Andrés Zaldivar en la primarias y al exceso de confianza de los líderes de los partidos de gobierno respecto al bajo perfil político que subjetivamente percibían que tenía Joaquín Lavín. Mientras Lavín sembraba la esperanza a los desposeídos con su "mensaje del cambio" en terreno, el candidato a la primera magistratura de la Concertación realizaba viajes al extranjero donde se entrevistaba con economistas, intelectuales y políticos comenzó a bajar en las encuestas. Esta constatación forzó a la Concertación a generar más propaganda estática y a iniciar sus trabajos en las "plazas ciudadanas", en que jóvenes profesionales expresaban a los pobladores cuáles eran los objetivos del programa de Ricardo Lagos.

El día 2 de noviembre de 1999, se realizó un debate presidencial entre Ricardo Lagos y Joaquín Lavín que fue trasmitido por la mayoría de los canales de televisión. Ambos candidatos mostraron sus fortalezas: Ricardo Lagos con la prestancia de un líder detrás del cual se esconden ideas y conceptos globales para manejar el país frente a un Joaquín Lavín más cercano y cálido, que con un lenguaje directo buscó inaugurar un nuevo tipo de liderazgo ${ }^{15}$. Las preguntas de los pe-

14 Nótese el mensaje subliminal que induce al observador la letra "a» sin destacar.

15 El Mercurio: Lavín y Lagos: vías paralelas, domingo 7/11/1999, Cuerpo D, pág. 1. 
riodistas selectos apuntaron a los grandes temas contenidos en los programas de gobierno de los candidatos, como la forma de disminuir la pobreza y la contaminación ambiental, los gastos de defensa, la censura, la solución al problema de los derechos humanos, en los cuales hubo coincidencias notables. Las diferencias se manifestaron en cuanto a la posición frente al indulto presidencial para los condenados a la pena de muerte, Joaquín Lavín fue enfático en señalar que no ejercería la facultad de indulto, en cambio Ricardo Lagos dijo que ejercería todos los poderes que la Constitución le otorgaría. Ricardo Lagos buscó consolidar su imagen como estadista usando sus dotes de gran orador mostrando seguridad en sus convicciones, haciendo emplazamientos a Joaquín Lavín con el propósito de desenmascarar inconsistencias y evasiones a preguntas formuladas por los periodistas. Joaquín Lavín evitó caer en la confrontación de ideas y se limitó a reproducir la estrategia preparada por sus asesores. Como una conclusión del debate, se podría decir que la habilidad de Joaquín Lavín no permitió a Ricardo Lagos lograr su objetivo de demostrar al país su superioridad, fue un empate. Los candidatos Hirsch y Marín se sintieron discriminados arbitrariamente por no haber sido invitados a participar en el debate, e incluso aquél interpuso un recurso de protección ${ }^{16}$ en contra de ANATEL ${ }^{17}$ y los canales de televisión para que la Corte impidiera la realización del debate.

Las fortalezas del candidato Lavín eran su lenguaje más coloquial y juvenil, su aire de renovación, apoliticidad, tecnicismo que abrigaba esperanzas de eficacia para solucionar los problemas, su catolicismo que él mismo llamaba en términos más generales "cristiandad común". El electorado católico y conservador veía una mejor imagen de familia en Lavín que en Lagos, fundada en un matrimonio constituido "según la ley de Dios" porque se había casado una sola vez y para siempre con María Estela León, con quien tuvo siete hijos, en cambio Lagos se había casado en segundas nupcias con Luisa Durán, fundando una "familia recompuesta" con una hija común. Las debilidades de Lavín eran la falta de experiencia en lides políticas $y$ su cercanía ideológica con el Senador Augusto Pinochet, aún detenido en Londres. El antídoto contra la primera flaqueza era sostener la tesis de que los políticos no servían para solucionar problemas de naturaleza económica, en cambio él con sus conocimientos y buenas ideas sí era idóneo, en tanto que para la segunda, optó por evitar

16 Acción de amparo de derechos fundamentales.

17 Asociación Nacional de Televisión. 
tocar el tema diciendo que no respondería a ataques en contra de su persona.

Las fortalezas del candidato Lagos eran su magnífica oratoria, su asertividad, su capacidad de liderazgo, su gran prestigio como político y Ministro de Educación en el Gobierno de Patricio Aylwin Azócar (1990-1994) y Ministro de Obras Públicas de Eduardo Frei Ruiz-Tagle (1994-2000). Sus debilidades eran su distancia intelectual y comunicacional con relación a las masas poco educadas, haber colaborado con el régimen de la Unidad Popular y el desgaste que sufre la coalición de gobierno ante la escasa eficiencia en solucionar los graves problemas socioeconómicos que afectaban a la familia chilena de clase media y baja. La mesura y responsabilidad con que Lagos prometía lograr sus objetivos contenidos en su plataforma electoral se veía opacada por las espectaculares ofertas y mejores resultados prometidos por Lavín, y el rechazo de los sectores católicos de corte conservador.

\subsubsection{Propagandas electorales}

La candidatura de centro-derecha efectuó un despliegue propagandístico en todo nivel: diarios, revistas, radios, gastando dinero como nunca antes se había visto en la historia electoral de Chile. Los afiches y pancartas de fondo azul con la consigna "Viva el cambio" de color amarilio, con la letra "a" de color blanco, aparecian en todos los postes de alumbrado público de las principales ciudades del país. La candidatura de centro-izquierda también acudió a la propaganda masiva, pero sus escasos recursos no le permitieron competir de igual a igual con la centro-derecha.

En Chile, existe una propaganda electoral gratuita para los candidatos a Presidente de la República, transmitida por los canales de televisión con carácter obligatorio ${ }^{18}$, que otorgó a cada candidato la posibilidad de exponer a los televidentes sus programas de gobierno en igualdad de condiciones. Mientras la derecha ideó una estrategia de presentar una campaña alegre y promisoria de satisfacer expectativas frustradas, cautivando a muchos indecisos con melodías hermosas, la Concertación mostró una faz demasiado confrontacional y dirigida más a descalificar a su principal adversario que a potenciar las virtudes de Lagos. Además, el lema "Crecer con lgualdad" era difícil de entender 
por los ciudadanos poco versados en la ciencia económica y en el derecho constitucional.

\subsubsection{Encuestas.}

En una encuesta del Centro de Estudios para el Desarrollo (CED) intitulada ¿por quién votarían si en las primarias perdiera Andrés Zaldivar?, los entrevistados respondieron de la siguiente manera: Ricardo Lagos 58,7\%; Joaquín Lavín 13,9 \%, Arturo Frei 2,2\%; Gladys Marín, 0,4\%, Nulo o blanco: $11,3 \%$; No votaría $6,5 \%$ y No responde:6,6\% ${ }^{19}$. En un sondeo realizado por la empresa Search-marketing entre el sábado 20 y el martes 23 de noviembre de 1999, 669 personas inscritas en los registros electorales fueron entrevistadas sobre las características personales de los candidatos, en las cuales las percepciones de los entrevistados se concentraron en Lagos y Lavín. Ante la consulta respecto a quien tiene mejores características para ser Presidente de la República, un $51 \%$ respondió que Lagos y un $38 \%$ que Lavin ${ }^{20}$.

\section{LOS RESULTADOS ELECTORALES EN LA PRIMERA VUELTA}

Durante la tarde del día 12 de diciembre de 1999, mientras se efectuaba el escrutinio en las primeras mesas electorales de varones, dio la impresión que Lagos ganaba de manera cómoda en primera vuelta, a tal punto que Genaro Arriagada, su "General» de campaña electoral dijo por televisión: "es claro que hay una diferencia irremontable para Lavín". Sin embargo, la proyección de la votación percibida por el Gobierno quedó desvirtuada por el aumento de las preferencias del electorado femenino por Joaquín Lavín. Luego de dos campañas presidenciales consecutivas en que la Concertación había ganado en la primera vuelta, era claro que la votación obtenida por Ricardo Lagos, a pesar de ser la más alta, no era suficiente para alcanzar la mayoría absoluta que exige nuestra Constitución. También sorprendió la escasa votación obtenida por los candidatos "pequeños".

19 El Mercurio: Detectan 5 causas en derrota de Zaldívar, miércoles 10/6/1999, Cuerpo C, pág. 3.

20 El Mercurio: Opiniones polarizadas en sondeo Search, Sábado 27/11/1999, Cuerpo C, pág. 3. 


\subsection{Cuadros estadísticos de los resultados}

\subsubsection{Cuadro por regiones}

\begin{tabular}{lrrrrrrrr}
\hline \multicolumn{7}{c}{ Elección Presidencial 1999 } \\
& \multicolumn{7}{c}{ Primera Vuelta. VOTACIÓN } \\
\hline Regiones & Arturo & \multicolumn{1}{c}{ Sara } & Gladys & Tomás & Ricardo & Joaquín & Total \\
& Frei & Larraín & Martín & Hirsch & Lagos & Lavín & región \\
\hline Tarapaca & 468 & 564 & 6.893 & 1.042 & 78.617 & 83.985 & 171.569 \\
Antofagasta & 608 & 671 & 8.140 & 1.093 & 107.504 & 80.527 & 198.543 \\
Atacama & 273 & 386 & 5.037 & 492 & 62.244 & 42.578 & 111.010 \\
Coquimbo & 1.026 & 1.297 & 9.230 & 1.249 & 148.558 & 100.985 & $\mathbf{2 6 2 . 3 4 5}$ \\
Valparaíso & 2.731 & 3.389 & 28.493 & 4.028 & 344.053 & 397.017 & $\mathbf{7 7 9 . 7 1 1}$ \\
O'H'iggins & 1.483 & 1.875 & 10.584 & 1.847 & 191.058 & 185.452 & $\mathbf{3 9 2 . 2 9 9}$ \\
Maule & 1.850 & 2.434 & 9.472 & 1.981 & 225.304 & 210.768 & $\mathbf{4 5 1 . 8 0 9}$ \\
Bío Bío & 5.583 & 4.957 & 29.932 & 4.957 & 463.597 & 402.291 & $\mathbf{9 1 1 . 3 1 7}$ \\
Araucanía & 2.047 & 2.151 & 6.679 & 1.962 & 161.045 & 225.279 & $\mathbf{3 9 9 . 1 6 3}$ \\
De los Lagos & 2.514 & 2.344 & 9.039 & 2.076 & 219.150 & 256.369 & $\mathbf{4 9 1 . 4 9 2}$ \\
lbañez & 217 & 198 & 914 & 191 & 18.805 & 20.609 & $\mathbf{4 0 . 9 3 4}$ \\
Magallanes & 256 & 248 & 1.748 & 364 & 40.169 & $\mathbf{3 1 . 2 9 7}$ & $\mathbf{7 4 . 0 8 2}$ \\
Metropolitana & 7.756 & 10.805 & 99.063 & 14.953 & 1.323 .235 & 1.315 .042 & $\mathbf{2 . 7 7 0 . 8 5 4}$ \\
Total candidato & $\mathbf{2 6 . 8 1 2}$ & $\mathbf{3 1 . 3 1 9}$ & $\mathbf{2 2 5 . 2 2 4}$ & $\mathbf{3 6 . 2 3 5}$ & $\mathbf{3 . 3 8 3 . 3 3 9}$ & $\mathbf{3 . 3 5 2 . 1 9 9}$ & $\mathbf{7 . 0 5 5 . 1 2 8}$ \\
\hline
\end{tabular}

\section{Elección Presidencial 1999}

Primera Vuelta. \% Porcentaje

\begin{tabular}{|c|c|c|c|c|c|c|c|}
\hline Regiones & $\begin{array}{c}\text { Arturo } \\
\text { Frei }\end{array}$ & $\begin{array}{c}\text { Sara } \\
\text { Larraín }\end{array}$ & $\begin{array}{l}\text { Gladys } \\
\text { Martín }\end{array}$ & $\begin{array}{l}\text { Tomás } \\
\text { Hirsch }\end{array}$ & $\begin{array}{c}\text { Ricardo } \\
\text { Lagos }\end{array}$ & $\begin{array}{c}\text { Joaquín } \\
\text { Lavín }\end{array}$ & $\begin{array}{c}\text { Total } \\
\text { región }\end{array}$ \\
\hline Tarapaca & $0,27 \%$ & $0,33 \%$ & $4,02 \%$ & $0,61 \%$ & $45,82 \%$ & $48,95 \%$ & $100 \%$ \\
\hline Antofagasta & $0,31 \%$ & $0,34 \%$ & $4,10 \%$ & $0,55 \%$ & $54,15 \%$ & $40,56 \%$ & $100 \%$ \\
\hline Atacama & $0,25 \%$ & $0,35 \%$ & $4,54 \%$ & $0,44 \%$ & $56,07 \%$ & $38,36 \%$ & $100 \%$ \\
\hline Coquimbo & $0,39 \%$ & $0,49 \%$ & $3,52 \%$ & $0,48 \%$ & $56,63 \%$ & $38,49 \%$ & $100 \%$ \\
\hline Valparaíso & $0,35 \%$ & $0,43 \%$ & $3,65 \%$ & $0,52 \%$ & $44,13 \%$ & $50,92 \%$ & $100 \%$ \\
\hline O'H'iggins & $0,38 \%$ & $0,48 \%$ & $2,70 \%$ & $0,47 \%$ & $48,70 \%$ & $47,27 \%$ & $100 \%$ \\
\hline Maule & $0,41 \%$ & $0,54 \%$ & $2,10 \%$ & $0,44 \%$ & $49,87 \%$ & $46,65 \%$ & $100 \%$ \\
\hline Bío Bío & $0,61 \%$ & $0,54 \%$ & $3,28 \%$ & $0,54 \%$ & $50,87 \%$ & $44,14 \%$ & $100 \%$ \\
\hline Araucanía & $0,51 \%$ & $0,54 \%$ & $1,67 \%$ & $0,49 \%$ & $40,35 \%$ & $56,44 \%$ & $100 \%$ \\
\hline De los Lagos & $0,51 \%$ & $0,48 \%$ & $1,84 \%$ & $0,42 \%$ & $44,59 \%$ & $52,16 \%$ & $100 \%$ \\
\hline Ibañez & $0,53 \%$ & $0,48 \%$ & $2,23 \%$ & $0,47 \%$ & $45,94 \%$ & $50,35 \%$ & $100 \%$ \\
\hline Magallanes & $0,35 \%$ & $0,33 \%$ & $2,36 \%$ & $0,49 \%$ & $54,22 \%$ & $42,25 \%$ & $100 \%$ \\
\hline Metropolitana & $0,28 \%$ & $0,39 \%$ & $3,58 \%$ & $0,54 \%$ & $47,76 \%$ & $47,46 \%$ & $100 \%$ \\
\hline Total candidato & $0,38 \%$ & $0,44 \%$ & $3,19 \%$ & $0,51 \%$ & $47,96 \%$ & $47,51 \%$ & $100 \%$ \\
\hline
\end{tabular}




\subsubsection{Cuadro de varones y mujeres}

\begin{tabular}{lrrrrrrrr}
\hline \multicolumn{7}{c}{ Elección Presidencial 1999 } \\
& \multicolumn{7}{c}{ Primera Vuelta. VOTACIÓN VARONES } \\
\hline Regiones & Arturo & \multicolumn{1}{c}{ Sara } & Gladys & Tomás & Ricardo & Joaquín & \multicolumn{1}{c}{ Total } \\
& Frei & Larraín & Martín & Hirsch & Lagos & Lavín & región \\
\hline Tarapaca & 246 & 230 & 3.722 & 551 & 40.080 & 38.545 & $\mathbf{8 3 . 3 7 4}$ \\
Antofagasta & 303 & 276 & 4.520 & 560 & 55.102 & 35.963 & $\mathbf{9 6 . 7 2 4}$ \\
Atacama & 149 & 175 & 2.821 & 279 & 31.914 & 18.352 & $\mathbf{5 3 . 6 9 0}$ \\
Coquimbo & 482 & 568 & 5.066 & 640 & 74.497 & 43.118 & $\mathbf{1 2 4 . 3 7 1}$ \\
Valparaíso & 1.400 & 1.492 & 15.699 & 2.071 & 172.106 & 171.831 & $\mathbf{3 6 4 . 5 9 9}$ \\
O'H'iggins & 763 & 939 & 6.060 & 977 & 100.077 & 82.249 & $\mathbf{1 9 1 . 0 6 5}$ \\
Maule & 918 & 1.200 & 5.380 & 1.065 & 116.218 & 93.520 & $\mathbf{2 1 8 . 3 0 1}$ \\
Bío Bío & 2.619 & 2.201 & 15.861 & 2.538 & 234.008 & 178.023 & $\mathbf{4 3 5 . 2 5 0}$ \\
Araucanía & 890 & 883 & 3.459 & 942 & 82.310 & 103.795 & $\mathbf{1 9 2 . 2 7 9}$ \\
De los Lagos & 1.164 & 1.043 & 4.817 & 1.073 & 112.157 & 119.344 & $\mathbf{2 3 9 . 5 9 8}$ \\
lbañez & 109 & 96 & 490 & 110 & 9.916 & 10.337 & $\mathbf{2 1 . 0 5 8}$ \\
Magallanes & 151 & 112 & 967 & 193 & 20.789 & 15.920 & $\mathbf{3 8 . 1 3 2}$ \\
Metropolitana & 3.861 & 4.681 & 53.999 & 7.635 & 644.914 & 557.581 & $\mathbf{1 . 2 7 2 . 6 7 1}$ \\
Total candidato & $\mathbf{1 3 . 0 5 5}$ & $\mathbf{1 3 . 8 9 6}$ & $\mathbf{1 2 2 . 8 6 1}$ & $\mathbf{1 8 . 6 3 4}$ & $\mathbf{1 . 6 9 4 . 0 8 8}$ & $\mathbf{1 . 4 6 8 . 5 7 8}$ & $\mathbf{3 . 3 3 1 . 1 1 2}$ \\
\hline
\end{tabular}

\section{Elección Presidencial 1999}

Primera Vuelta. \% Porcentaje Varones

\begin{tabular}{lccccccc}
\hline Regiones & $\begin{array}{c}\text { Arturo } \\
\text { Frei }\end{array}$ & $\begin{array}{c}\text { Sara } \\
\text { Larrain }\end{array}$ & $\begin{array}{c}\text { Gladys } \\
\text { Martín }\end{array}$ & $\begin{array}{c}\text { Tomás } \\
\text { Hirsch }\end{array}$ & $\begin{array}{c}\text { Ricardo } \\
\text { Lagos }\end{array}$ & $\begin{array}{c}\text { Joaquín } \\
\text { Lavín }\end{array}$ & $\begin{array}{c}\text { Total } \\
\text { región }\end{array}$ \\
\hline Tarapaca & $0,30 \%$ & $0,28 \%$ & $4,46 \%$ & $0,66 \%$ & $48,07 \%$ & $46,23 \%$ & $100 \%$ \\
Antofagasta & $0,31 \%$ & $0,29 \%$ & $4,67 \%$ & $0,58 \%$ & $56,97 \%$ & $37,18 \%$ & $100 \%$ \\
Atacama & $0,28 \%$ & $0,33 \%$ & $5,25 \%$ & $0,52 \%$ & $59,44 \%$ & $34,18 \%$ & $100 \%$ \\
Coquimbo & $0,39 \%$ & $0,46 \%$ & $4,07 \%$ & $0,51 \%$ & $59,90 \%$ & $34,67 \%$ & $100 \%$ \\
Valparaíso & $0,38 \%$ & $0,41 \%$ & $4,31 \%$ & $0,57 \%$ & $47,20 \%$ & $47,13 \%$ & $100 \%$ \\
O'H'iggins & $0,40 \%$ & $0,49 \%$ & $3,17 \%$ & $0,51 \%$ & $52,38 \%$ & $43,05 \%$ & $100 \%$ \\
Maule & $0,42 \%$ & $0,55 \%$ & $2,46 \%$ & $0,49 \%$ & $53,24 \%$ & $42,84 \%$ & $100 \%$ \\
Bío Bío & $0,60 \%$ & $0,51 \%$ & $3,64 \%$ & $0,58 \%$ & $53,76 \%$ & $40,90 \%$ & $100 \%$ \\
Araucanía & $0,46 \%$ & $0,46 \%$ & $1,80 \%$ & $0,49 \%$ & $42,81 \%$ & $53,98 \%$ & $100 \%$ \\
De los Lagos & $0,49 \%$ & $0,44 \%$ & $2,01 \%$ & $0,45 \%$ & $46,81 \%$ & $49,81 \%$ & $100 \%$ \\
Ibañez & $0,52 \%$ & $0,46 \%$ & $2,33 \%$ & $0,52 \%$ & $47,09 \%$ & $49,09 \%$ & $100 \%$ \\
Magallanes & $0,40 \%$ & $0,29 \%$ & $2,54 \%$ & $0,51 \%$ & $54,52 \%$ & $41,75 \%$ & $100 \%$ \\
Metropolitana & $0,30 \%$ & $0,37 \%$ & $4,24 \%$ & $0,60 \%$ & $50,67 \%$ & $43,81 \%$ & $100 \%$ \\
Total candidato & $\mathbf{0 , 3 9} \%$ & $\mathbf{0 , 4 2} \%$ & $\mathbf{3 , 6 9} \%$ & $\mathbf{0 , 5 6 \%}$ & $\mathbf{5 0 , 8 6 \%}$ & $\mathbf{4 4 , 0 9} \%$ & $\mathbf{1 0 0 \%}$ \\
\hline
\end{tabular}




\begin{tabular}{lrrrrrrr}
\hline \multicolumn{7}{c}{ Elección Presidencial 1999 } \\
\hline \multicolumn{7}{c}{ Primera Vuelta. VOTACIÓN } & MUJERES \\
\hline Regiones & Arturo & \multicolumn{1}{c}{ Sara } & Gladys & Tomás & Ricardo & Joaquín & \multicolumn{1}{c}{ Total } \\
& Frei & Larraín & Martín & Hirsch & Lagos & Lavín & región \\
\hline Tarapaca & 222 & 334 & 3.171 & 491 & 38.537 & 45.440 & $\mathbf{8 8 . 1 9 5}$ \\
Antofagasta & 305 & 395 & 3.620 & 533 & 52.402 & 44.564 & 101.819 \\
Atacama & 124 & 211 & 2.216 & 213 & 30.330 & 24.226 & $\mathbf{5 7 . 3 2 0}$ \\
Coquimbo & 544 & 729 & 4.164 & 609 & 74.061 & 57.867 & $\mathbf{1 3 7 . 9 7 4}$ \\
Valparaíso & 1.331 & 1.897 & 12.794 & 1.957 & 171.947 & 225.186 & $\mathbf{4 1 5 . 1 1 2}$ \\
O'H'iggins & 720 & 936 & 4.524 & 870 & 90.981 & 103.203 & $\mathbf{2 0 1 . 2 3 4}$ \\
Maule & 932 & 1.234 & 4.092 & 916 & 109.086 & 117.248 & $\mathbf{2 3 3 . 5 0 8}$ \\
Bío Bío & 2.964 & 2.756 & 14.071 & 2.419 & 229.589 & 224.268 & $\mathbf{4 7 6 . 0 6 7}$ \\
Araucanía & 1.157 & 1.268 & 3.220 & 1.020 & 78.735 & 121.484 & $\mathbf{2 0 6 . 8 8 4}$ \\
De los Lagos & 1.350 & 1.301 & 4.222 & 1.003 & 106.993 & 137.025 & $\mathbf{2 5 1 . 8 9 4}$ \\
lbañez & 108 & 102 & 424 & 81 & 8.889 & 10.272 & $\mathbf{1 9 . 8 7 6}$ \\
Magallanes & 105 & 136 & 781 & 171 & 19.380 & 15.377 & $\mathbf{3 5 . 9 5 0}$ \\
Metropolitana & 3.895 & 6.124 & 45.064 & 7.318 & 678.321 & 757.461 & $\mathbf{1 . 4 9 8 . 1 8 3}$ \\
Total candidato & 13.757 & 17.423 & 102.363 & 17.601 & 1.689 .251 & 1.883 .621 & $\mathbf{3 . 7 2 4 . 0 1 6}$ \\
\hline
\end{tabular}

Elección Presidencial 1999

Primera Vuelta. \% Porcentaje Mujeres

\begin{tabular}{|c|c|c|c|c|c|c|c|}
\hline Regiones & $\begin{array}{c}\text { Arturo } \\
\text { Frei }\end{array}$ & $\begin{array}{c}\text { Sara } \\
\text { Larraín }\end{array}$ & $\begin{array}{l}\text { Gladys } \\
\text { Martín }\end{array}$ & $\begin{array}{l}\text { Tomás } \\
\text { Hirsch }\end{array}$ & $\begin{array}{c}\text { Ricardo } \\
\text { Lagos }\end{array}$ & $\begin{array}{c}\text { Joaquín } \\
\text { Lavín }\end{array}$ & $\begin{array}{l}\text { Total } \\
\text { región }\end{array}$ \\
\hline Tarapaca & $0,25 \%$ & $0,38 \%$ & $3,60 \%$ & $0,56 \%$ & $43,70 \%$ & $51,52 \%$ & $100 \%$ \\
\hline Antofagasta & $0,30 \%$ & $0,39 \%$ & $3,56 \%$ & $0,52 \%$ & $51,47 \%$ & $43,77 \%$ & $100 \%$ \\
\hline Atacama & $0,22 \%$ & $0,37 \%$ & $3,87 \%$ & $0,37 \%$ & $52,91 \%$ & $42,26 \%$ & $100 \%$ \\
\hline Coquimbo & $0,39 \%$ & $0,53 \%$ & $3,02 \%$ & $0,44 \%$ & $53,68 \%$ & $41,94 \%$ & $100 \%$ \\
\hline Valparaíso & $0,32 \%$ & $0,46 \%$ & $3,08 \%$ & $0,47 \%$ & $41,42 \%$ & $54,25 \%$ & $100 \%$ \\
\hline $\mathrm{O}^{\prime} \mathrm{H}^{\prime}$ iggins & $0,36 \%$ & $0,47 \%$ & $2,25 \%$ & $0,43 \%$ & $45,21 \%$ & $51,29 \%$ & $100 \%$ \\
\hline Maule & $0,40 \%$ & $0,53 \%$ & $1,75 \%$ & $0,39 \%$ & $46,72 \%$ & $50,21 \%$ & $100 \%$ \\
\hline Bío Bío & $0,62 \%$ & $0,58 \%$ & $2,96 \%$ & $0,51 \%$ & $48,23 \%$ & $47,11 \%$ & $100 \%$ \\
\hline Araucanía & $0,56 \%$ & $0,61 \%$ & $1,56 \%$ & $0,49 \%$ & $38,06 \%$ & $58,72 \%$ & $100 \%$ \\
\hline De los Lagos & $0,54 \%$ & $0,52 \%$ & $1,68 \%$ & $0,40 \%$ & $42,48 \%$ & $54,40 \%$ & $100 \%$ \\
\hline Ibañez & $0,54 \%$ & $0,51 \%$ & $2,13 \%$ & $0,41 \%$ & $44,72 \%$ & $51,68 \%$ & $100 \%$ \\
\hline Magallanes & $0,29 \%$ & $0,38 \%$ & $2,17 \%$ & $0,48 \%$ & $53,91 \%$ & $42,77 \%$ & $100 \%$ \\
\hline Metropolitana & $0,26 \%$ & $0,41 \%$ & $3,01 \%$ & $0,49 \%$ & $45,28 \%$ & $50,56 \%$ & $100 \%$ \\
\hline Total candidato & $0,37 \%$ & $0,47 \%$ & $2,75 \%$ & $0,47 \%$ & $45,36 \%$ & $50,58 \%$ & $100 \%$ \\
\hline
\end{tabular}




\subsection{Análisis de los resultados}

El primer análisis de la elección presidencial 1999 es que por tercera vez consecutiva se produce una competición electoral entre sólo dos fuerzas políticas grandes: la centro-derecha opositora y la centroizquierda gobernante, que desde ningún punto de vista fueron polarizadas, ya que a pesar de sus diferencias políticas y de valores, sus programas de gobierno eran muy parecidos, lo que dio tranquilidad a la ciudadanía en el sentido que ni Joaquín Lavín encarnaba el regreso del gobierno militar de Pinochet, ni Ricardo Lagos la repetición de la Unidad Popular de Allende, tesis sustentada por Andrés Allamand ${ }^{21}$ a los medios de comunicación social en el Aeropuerto Internacional, a su llegada de Estados Unidos días antes de la primera vuelta.

El segundo análisis de la elección presidencial 1999, que es consecuencia del anterior, apunta a la escasa votación obtenida por los candidatos "pequeños" Arturo Frei, Sara Larraín, Gladys Marín y Tomás Hirsch, que fue menor de la esperada al no superar en conjunto el 4,52 por ciento del total de los votos escrutados, excluidos los nulos y los blancos. Por otra parte, la constatación de que los candidatos "pequeños" nunca tuvieron posibilidades serias de ganar la elección presidencial, nos permite formular con autoridad una crítica a la Ley N. ${ }^{\circ} 18.700$ por la excesiva generosidad con que permite declarar e inscribir candidaturas a la Presidencia de la República, situación que a nuestro juicio produce un aumento en los costos económicos del proceso electoral y obliga a los electores a concurrir a dos elecciones que bien pudieron evitarse con un solo acto eleccionario. Asimismo, llama la atención que el candidato independiente Arturo Frei, con un 0,3 por ciento, que con anterioridad a la primera vuelta obtuvo la inscripción de su candidatura en virtud de un 0,5 por ciento, registró una votación inferior al mínimo de firmas que exige nuestra ley electoral para inscribir las candidaturas independientes a Presidente de la República. ${ }^{22}$

\section{REACCIONES Y ESTRATEGIAS DE LAS DOS CANDIDATURAS QUE OBTUVIERON LAS MÁS ALTAS MAYORÍAS RELATIVAS}

La centro-derecha sintió un halo de triunfo por la alta votación obtenida por Joaquín Lavín, que superaba con creces el porcentaje ob-

21 Es un ex presidente del partido de derecha Renovación Nacional, de gran prestigio incluso en la Concertación, por exigir al gobierno de Augusto Pinochet que reconociera su derrota en el plebiscito del Sí y el No en 1988, y por su política de los acuerdos de la oposición con el gobierno de la Concertación para fortalecer el sistema democrático republicano.

${ }^{22}$ Supra: 1. EL SISTEMA ELECTORAL CHILENO. 
tenido por Augusto Pinochet en el plebiscito del "Sí y el No" de 1988, y mantuvo su equipo de trabajo, modificando su lema "Únete al Cambio, con tu voto más un voto". La Concertación tomó la decisión de persuadir a su Ministra de Justicia, la demócrata-cristiana Soledad Alvear, para que asumiera la jefatura de la campaña de la concertación y captara el voto femenino que fue esquivo para Ricardo Lagos. El lema ahora era "Chile, mucho mejor". Tomás Hirch y Sara Larraín llamaron a los ciudadanos que votaron por ellos que respaldaran a Ricardo Lagos, en tanto que Gladys Marín llamó a sus camaradas comunistas a votar nulo, pero la mayoría de la izquierda no concertacionista, que presagiaban un triunfo de la derecha en la segunda vuelta, se unieron para gritar: ¡A parar a la Derecha!, ante la soberbia de la cúpula de izquierda que llamaría a votar nulo en una segunda vuelta, sus bases apoyaron a Lagos por temor al triunfo de la derecha ${ }^{23}$. Arturo Frei Bolívar llamó a sus simpatizantes a votar por Joaquín Lavín.

\section{RESULTADOS ELECTORALES EN LA SEGUNDA VUELTA}

\subsection{Cuadros estadísticos de los resultados}

\subsubsection{Cuadro por regiones}

\begin{tabular}{|c|c|c|c|c|c|}
\hline \multicolumn{6}{|c|}{ Segunda Vuelta. VOTACIÓN } \\
\hline Regiones & $\begin{array}{c}\text { Ricardo } \\
\text { Lagos }\end{array}$ & $\begin{array}{c}\% \\
\text { Porcentaje }\end{array}$ & $\begin{array}{l}\text { Joaquín } \\
\text { Lavin }\end{array}$ & $\begin{array}{c}\% \\
\text { Porcentaje }\end{array}$ & $\begin{array}{c}\text { Total } \\
\text { Región }\end{array}$ \\
\hline Tarapaca & 85.792 & $49,43 \%$ & 87.766 & $50,57 \%$ & 173.558 \\
\hline Antofagasta & 116.008 & $58,05 \%$ & 83.831 & $41,95 \%$ & 199.839 \\
\hline Atacama & 67.745 & $59,82 \%$ & 45.498 & $40,18 \%$ & 113.243 \\
\hline Coquimbo & 161.302 & $60,04 \%$ & 107.352 & $39,96 \%$ & 268.654 \\
\hline Valparaiso & 380.521 & $47,92 \%$ & 413.553 & $52,08 \%$ & 794.074 \\
\hline $\mathrm{O}^{\prime} \mathrm{H}^{\prime}$ iggins & 207.900 & $52,05 \%$ & 191.507 & $47,95 \%$ & 399.407 \\
\hline Maule & 240.825 & $52,03 \%$ & 222.062 & $47,97 \%$ & 462.887 \\
\hline Bío Bío & 510.035 & $54,58 \%$ & 424.453 & $45,42 \%$ & 934,488 \\
\hline Araucanía & 177.776 & $42,97 \%$ & 235.959 & $57,03 \%$ & 413.735 \\
\hline De los Lagos & 238.745 & $47,17 \%$ & 267.387 & $52,83 \%$ & 506.132 \\
\hline Ibañez & 19.726 & $47,66 \%$ & 21.659 & $52,34 \%$ & 41.385 \\
\hline Magallanes & 41.273 & $56,04 \%$ & 32.378 & $43,96 \%$ & 73.651 \\
\hline Metropolitana & 1.435 .510 & $51,31 \%$ & 1.362 .164 & $48,69 \%$ & 2.797 .674 \\
\hline Total candidato & 3.683 .158 & $51,31 \%$ & 3.495 .569 & $48,69 \%$ & 7.178.727 \\
\hline
\end{tabular}

23 La Firme: Portada, 14/12/99, pág. 1. 


\begin{tabular}{lrcccr}
\hline \multicolumn{5}{c}{ Elección Presidencial 1999 } \\
Regiones & Segunda Vuelta. & VOTACIÓN VARONES & \\
& Ricardo & $\%$ & Joaquín & $\%$ & \multicolumn{1}{c}{ Total } \\
\hline Tarapaca & 43755 & Porcentaje & Lavín & Porcentaje & Región \\
\hline Antofagasta & 59626 & $60,94 \%$ & 40973 & $48,36 \%$ & $\mathbf{8 4 . 7 2 8}$ \\
Atacama & 34975 & $63,60 \%$ & 38225 & $39,06 \%$ & $\mathbf{9 7 . 8 5 1}$ \\
Coquimbo & 80997 & $63,50 \%$ & 40021 & $36,40 \%$ & $\mathbf{5 4 . 9 9 6}$ \\
Valparaíso & 190292 & $51,18 \%$ & 181530 & $48,82 \%$ & $\mathbf{3 7 1 . 8 2 2}$ \\
O'H'iggins & 108577 & $55,70 \%$ & 86352 & $44,30 \%$ & $\mathbf{1 9 4 . 9 2 9}$ \\
Maule & 124171 & $55,46 \%$ & 99737 & $44,54 \%$ & $\mathbf{2 2 3 . 9 0 8}$ \\
Bío Bío & 256396 & $57,38 \%$ & 190479 & $42,62 \%$ & $\mathbf{4 4 6 . 8 7 5}$ \\
Araucanía & 90161 & $45,17 \%$ & 109454 & $54,83 \%$ & $\mathbf{1 9 9 . 6 1 5}$ \\
De los Lagos & 121659 & $49,20 \%$ & 125639 & $50,80 \%$ & $\mathbf{2 4 7 . 2 9 8}$ \\
lbañez & 10387 & $48,34 \%$ & 11100 & $51,66 \%$ & $\mathbf{2 1 . 4 8 7}$ \\
Magallanes & 21541 & $55,84 \%$ & 17034 & $44,16 \%$ & $\mathbf{3 8 . 5 7 5}$ \\
Metropolitana & 701296 & $54,44 \%$ & 586947 & $45,56 \%$ & $\mathbf{1 . 2 8 8 . 2 4 3}$ \\
Total candidato & $\mathbf{1 . 8 4 3 . 8 3 3}$ & $\mathbf{5 4 , 2 6 \%}$ & $\mathbf{1 . 5 5 4 . 0 4 6}$ & $\mathbf{4 5 , 7 4 \%}$ & $\mathbf{3 . 3 9 7 . 8 7 9}$ \\
\hline
\end{tabular}

\subsubsection{Cuadro de varones y mujeres}

\section{Elección Presidencial 1999}

Segunda Vuelta. VOTACIÓN MUJERES

\begin{tabular}{lrcccr}
\hline Regiones & $\begin{array}{c}\text { Ricardo } \\
\text { Lagos }\end{array}$ & $\begin{array}{c}\% \\
\text { Porcentaje }\end{array}$ & $\begin{array}{c}\text { Joaquín } \\
\text { Lavín }\end{array}$ & $\begin{array}{c}\% \\
\text { Porcentaje }\end{array}$ & $\begin{array}{c}\text { Total } \\
\text { Región }\end{array}$ \\
\hline Tarapaca & 42.037 & $47,32 \%$ & 46.793 & $52,68 \%$ & $\mathbf{8 8 . 8 3 0}$ \\
Antofagasta & 56.382 & $55,28 \%$ & 45.606 & $44,72 \%$ & $\mathbf{1 0 1 . 9 8 8}$ \\
Atacama & 32.770 & $56,26 \%$ & 25.477 & $43,74 \%$ & $\mathbf{5 8 . 2 4 7}$ \\
Coquimbo & 80.305 & $56,91 \%$ & 60.797 & $43,09 \%$ & $\mathbf{1 4 1 . 1 0 2}$ \\
Valparaiso & 190.229 & $45,05 \%$ & 232.023 & $54,95 \%$ & $\mathbf{4 2 2 . 2 5 2}$ \\
O'H'iggins & 99.323 & $48,57 \%$ & 105.155 & $51,43 \%$ & $\mathbf{2 0 4 . 4 7 8}$ \\
Maule & 116.654 & $48,81 \%$ & 122.325 & $51,19 \%$ & $\mathbf{2 3 8 . 9 7 9}$ \\
Bío Bío & 253.639 & $52,02 \%$ & 233.974 & $47,98 \%$ & $\mathbf{4 8 7 . 6 1 3}$ \\
Araucanía & 87.615 & $40,92 \%$ & 126.505 & $\mathbf{5 9 , 0 8 \%}$ & $\mathbf{2 1 4 . 1 2 0}$ \\
De los Lagos & 117.086 & $45,24 \%$ & 141.748 & $54,76 \%$ & $\mathbf{2 5 8 . 8 3 4}$ \\
lbañez & 9.339 & $46,93 \%$ & 10.559 & $53,07 \%$ & $\mathbf{1 9 . 8 9 8}$ \\
Magallanes & 19.732 & $\mathbf{5 6 , 2 5 \%}$ & 15.344 & $43,75 \%$ & $\mathbf{3 5 . 0 7 6}$ \\
Metropolitana & 734.214 & $48,64 \%$ & 775.217 & $51,36 \%$ & $\mathbf{1 . 5 0 9 . 4 3 1}$ \\
Total candidato & $\mathbf{1 . 8 3 9 . 3 2 5}$ & $\mathbf{4 8 , 6 5 \%}$ & $\mathbf{1 . 9 4 1 . 5 2 3}$ & $\mathbf{5 1 , 3 5 \%}$ & $\mathbf{3 . 7 8 0 . 8 4 8}$ \\
\hline
\end{tabular}


5.1.3. Cuadro de la votación de varones y mujeres en las elecciones de diciembre-1999/enero-2000 en relación con la de 1993

\begin{tabular}{|c|c|c|c|}
\hline \multicolumn{4}{|c|}{ Elección presidencial 1993} \\
\hline & Varones & Mujeres & Total \\
\hline Eduardo Frei & $733.466(46,36 \%)$ & $848.568(53,64 \%)$ & 1.582 .034 \\
\hline \multicolumn{4}{|c|}{ Elección presidencial 1999} \\
\hline Ricardo Lagos & $1.843 .833(50,10 \%)$ & $1.839 .325(49,90 \%)$ & 3.683 .158 \\
\hline
\end{tabular}

5.1.4. Cuadro de las elecciones de diciembre-1999/enero-2000 en relación con las de 1989 y 1993

\begin{tabular}{|c|c|c|c|c|c|}
\hline \multicolumn{2}{|c|}{1989} & \multicolumn{2}{|c|}{1993} & \multicolumn{2}{|c|}{$1999^{24}$} \\
\hline $\begin{array}{l}\text { P. Aylwin: } \\
\text { H. Buchi: }\end{array}$ & $\begin{array}{l}55,17 \% \\
29,40 \%\end{array}$ & $\begin{array}{l}\text { E. Frei R.: } \\
\text { A. Alessandri B.: }\end{array}$ & $\begin{array}{l}58,01 \% \\
24,39 \%\end{array}$ & $\begin{array}{l}\text { R. Lagos: } \\
\text { J. Lavin: }\end{array}$ & $\begin{array}{l}51,32 \% \\
48,68 \%\end{array}$ \\
\hline
\end{tabular}

\section{LAS REPERCUSIONES POLÍTICAS}

A nuestro juicio, la primera repercusión política de la elección presidencial 1999/2000 es la confianza en un candidato socialista que tiene el electorado chileno, luego del retorno a la democracia con los Presidentes demócrata-cristianos Patricio Aylwin y Eduardo Frei, dejando en el pasado el temor al regreso de una nueva versión de la Unidad Popular de los años 1970-1973.

En la elección 1999, el electorado dio prioridad a las características personales de cada candidato y no a la tendencia política que representaban. El triunfo de Ricardo Lagos se debió más a la figura del propio Ricardo Lagos que al respaldo de la ciudadanía a los partidos políticos que constituían la base de su candidatura, en otras palabras, queda refutada la "teoría de los tres tercios", que sostiene la tesis de que electorado chileno se divide en tres tercios cautivos y rígidos, el primero favorable a la derecha, el segundo demócrata-cristiano y el tercero de izquierda, al quedar demostrado en la primera vuelta la ducti- 
lidad del voto del electorado que anteriormente había votado por los demócrata-cristianos Patricio Aylwin y Eduardo Frei y que sumados al voto seguro o "duro" de la izquierda les permitiéndoles a éstos alcanzar la primera magistratura en la primera vuelta, mientras que Ricardo Lagos debió esperar el desenlace incierto de la segunda vuelta. Lagos tuvo la virtud de sostener la imagen de credibilidad pública, cohesión y viabilidad de la Concertación de Partidos por la Democracia como alianza política de gobierno, coalición que gana una elección presidencial por tercera vez consecutiva, no obstante la heterogeneidad ideológica de los partidos que la integran y el mal momento que afectaba a la economía chilena durante el proceso eleccionario.

La segunda repercusión política de la elección presidencial 1999/2000 es el aumento significativo de la votación obtenida por el candidato de la derecha opositora, que demuestra la efectividad de una activa campaña presidencial, y que enciende una luz de esperanza a sus seguidores en su postulación para las elecciones presidenciales del año 2005.

También llama la atención que el electorado femenino haya disminuido su preferencia por el candidato de la Concertación con relación a las elecciones de 1989 y 1993, cuya causa probable podemos encontrarla en la gran capacidad comunicacional de Joaquín Lavín, su lenguaje directo que logró mostrar más preocupación por los problemas contingentes en materia social y económica, tales como la seguridad ciudadana, disminuir el desempleo, y no tanto en debatir sobre temas políticos referidos a reformas constitucionales sobre supresión de los senadores vitalicios, a los que dio demasiado énfasis Ricardo Lagos.

Finalmente, es importante destacar que la victoria del candidato de la Concertación asegura a esta coalición un escaño en el Senado, por derecho propio y con carácter vitalicio a que tienen derecho los ex-Presidentes de la República ${ }^{25}$, y si agregamos que la incorporación de Eduardo Frei a la Cámara Alta como senador vitalicio, la Concertación rompe el equilibrio nominal a su favor por primera vez desde 1990, puede originar que la derecha opositora, por razones de conveniencia política, abra la posibilidad de debatir la propuesta de supresión de los senadores designados y vitalicios propuesta en tantas fallidas oportunidades por el gobierno.

25 El artículo 45 letra a) de la Constitución exige que hayan desempeñado el cargo durante seis años en forma continua, salvo que hubiese tenido lugar lo previsto en el número $1 .^{\circ}$ del artículo 49 de esta Constitución, esto es, que no haya sido declarado culpable por dos tercios de los senadores en ejercicio por una acusación "constitucional» en su contra. 